\title{
The Panther Chameleon, Furcifer pardalis (Cuvier 1829) (Chamaeleonidae), Another Introduced Chameleon Species in Florida
}

Michael R. Rochford ${ }^{1}$, Jake R. Edwards ${ }^{2}$, Patricia L. Howell ${ }^{3}$, Jennifer Ketterlin Eckles ${ }^{2}$, Liz A. Barraco ${ }^{2}$, Laurence L. Connor ${ }^{4}$, Michelle J. Curtis ${ }^{1}$, Kenneth L. Krysko ${ }^{5}$, and Frank J. Mazzotti ${ }^{1}$

${ }^{1}$ University of Florida, Fort Lauderdale Research and Education Center, 3205 College Avenue, Fort Lauderdale, Florida 33314, USA (MRR: miker@ufl.edu, FJM: fjma@ufl.edu) ${ }^{2}$ Florida Fish and Wildlife Conservation Commission, 3205 College Avenue, Fort Lauderdale, Florida 33314, USA (JRE: jake.edwards@myfwc.com, JKE: jennifer.eckles@myfwc.com, LB: liz.barraco@myfwc.com)

${ }^{3}$ Broward County Parks and Recreation, Natural Resources and Land Management Section, 950 NW, 38 Street, Oakland Park, Florida 33309, USA (phowell@broward.org) ${ }^{4}$ Florida Fish and Wildlife Conservation Commission, 601 West Woodward Avenue, Eustis, Florida 32726, USA (larry.connor@myfwc.com)

${ }^{5}$ Division of Herpetology, Florida Museum of Natural History, University of Florida, 1659 Museum Road, Gainesville, Florida 32611, USA (kenneyk@ufl.edu)

The Panther Chameleon, Furcifer pardalis (Cuvier 1829), 1 is indigenous to Madagascar, where it is found most commonly along riverine habitats and forest-like bands along roads (Andreone et al. 2005). Males from northwestern Madagascar can reach $229 \mathrm{~mm}$ in snout-vent length (SVL) and are generally larger than females (Andreone et al.

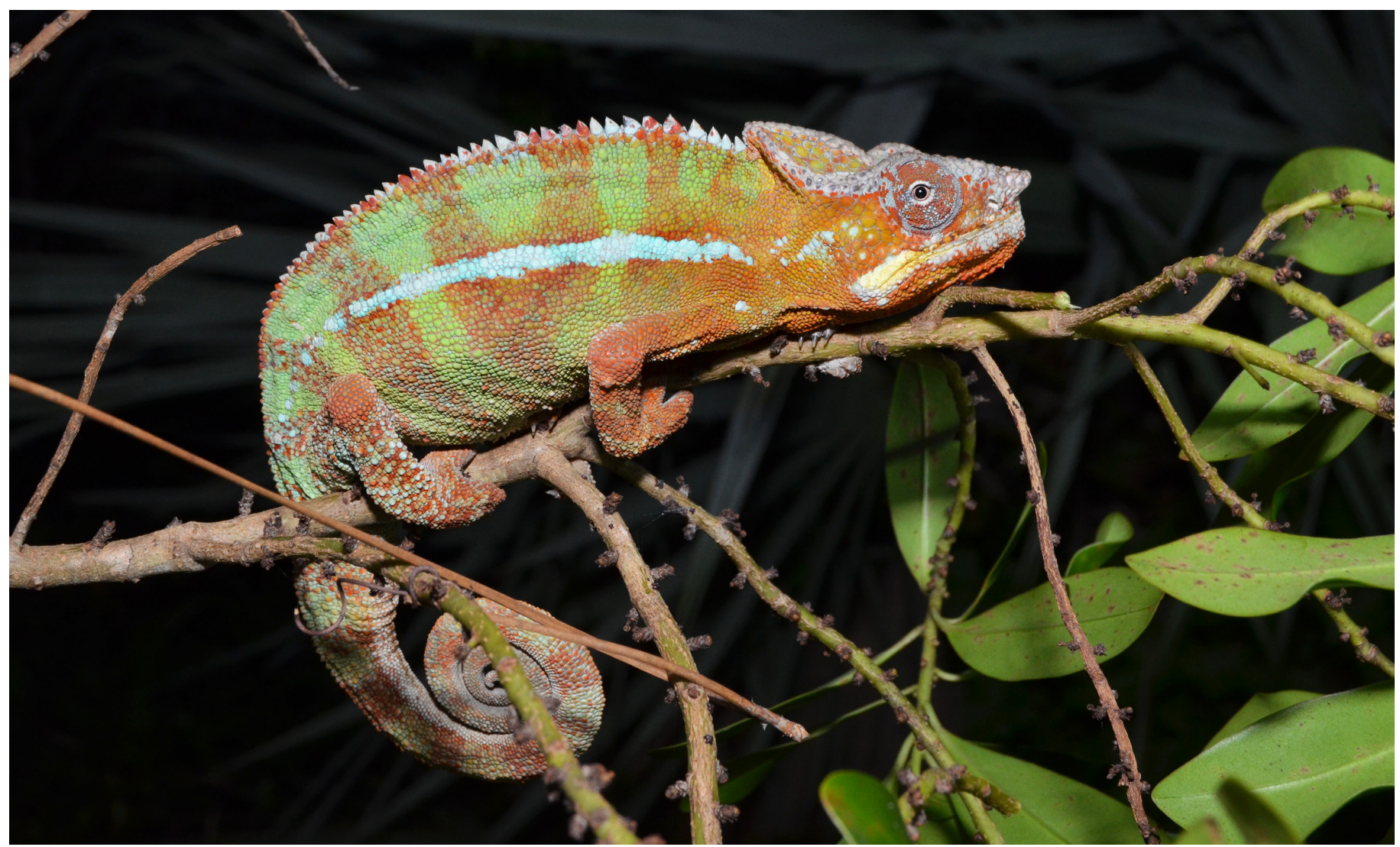

Fig. 1. Adult male Panther Chameleon (Furcifer pardalis) (UF-Herpetology 170801), collected on 10 July 2013 in Coconut Creek, Broward County, Florida. Photograph by Michael R. Rochford. 
2005). A single $F$. pardalis was introduced in DeSoto County, Florida, USA (Krysko et al. 2011), but it appeared to be an isolated individual. Herein, we report six $F$. pardalis from a small area in Broward County, Florida, that may represent a group of released or escaped animals or an incipient, reproducing population.

On 10 July 2013, PLH reported to the Early Detection and Distribution Mapping System (EDDMapS, www.eddmaps.org) an adult male Furcifer pardalis (photographic voucher UF-Herpetology 170801) from the Helene Klein Nature Preserve at $4701 \mathrm{~W}$. Hillsboro Boulevard, Coconut Creek, Broward County, Florida $\left(26.31881^{\circ} \mathrm{N}, 80.18952^{\circ} \mathrm{W}\right.$, Datum WGS84, 5 m elevation). On 11 July 2013, a perimeter night-time survey of this property was conducted by MRR and JRE; it resulted in one sub-adult female $F$. pardalis (photographic voucher UF-Herpetology 170802) sleeping on a Gumbo-limbo (Bursera simaruba) ca. $2 \mathrm{~m}$ above the ground at $2056 \mathrm{~h}\left(26.31937^{\circ} \mathrm{N}, 80.18777^{\circ} \mathrm{W}\right)$. On 21 July 2013 , during another night-time survey, a local resident approached MRR, JRE, JKE, and PLH, and without solicitation asked if we were looking for chameleons. The resident informed us that he had found two chameleons DOR on NW 71st
Place where it borders the northern side of the Helene Klein Pineland Preserve. On 31 July 2013, MRR contacted the pastor at North Creek Presbyterian Church, 4601 NW 71st Place, and was told that his wife had found a single adult male F. pardalis (photographic voucher UF-Herpetology 170514) on 1 June 2013 on the church walkway $\left(26.31996^{\circ} \mathrm{N}\right.$, $\left.80.18689^{\circ} \mathrm{W}\right)$. On 31 July 2013 , we conducted a nighttime survey of the church grounds and found a sub-adult female $F$. pardalis (photographic voucher UF-Herpetology 170526) sleeping on an Oak (Quercus sp.) ca. $3 \mathrm{~m}$ above the ground $\left(26.32037^{\circ} \mathrm{N}, 80.18803^{\circ} \mathrm{W}\right)$. Digital images of our live chameleons were sent to Christopher V. Anderson (pers. comm.), who confirmed our identification. In total, we spent 46.45 man-hours to find two $F$. pardalis, however, much of this time was spent away from the core area in an effort to determine the geographic limits of this biological invasion.

At least six $F$. pardalis, including adults and juveniles of both sexes, have been found within $300 \mathrm{~m}$ of each other, suggesting that they might represent a reproducing population. This population might have been extirpated, or it could be persisting in low numbers. If this species has indeed reproduced there, more individuals could be found over long

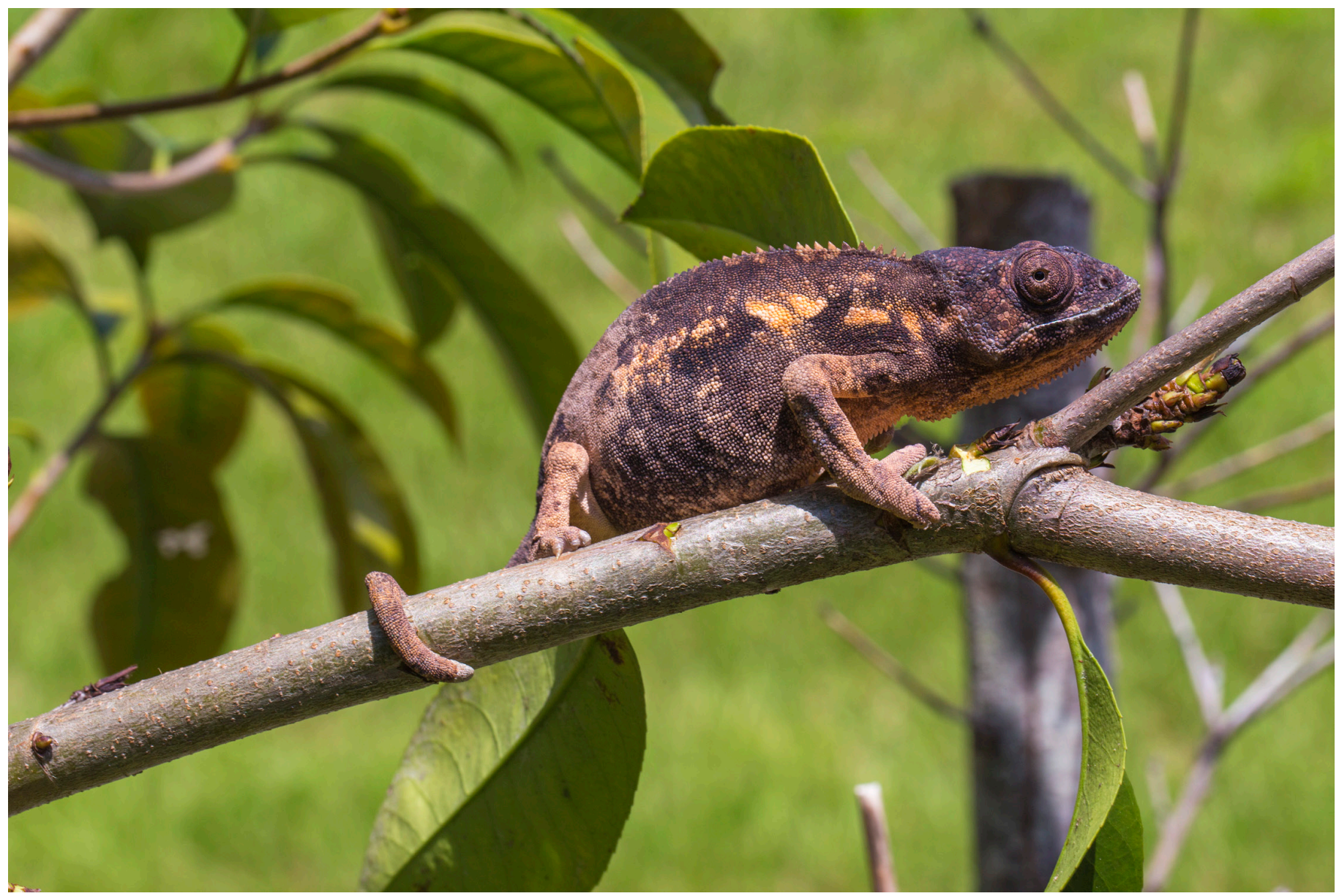

Fig. 2. Female Panther Chameleon (Furcifer pardalis) (UF-Herpetology 170802), collected on 11 July 2013 in Coconut Creek, Broward County, Florida. Photograph by Kenneth L. Krysko. 
periods of time in the same fashion as the invasion of the Veiled Chameleon (Chamaeleo calyptratus), in Fort Myers, Lee County, Florida (Krysko et al. 2004). Despite continued removal of all C. calyptratus found at that site, chameleons are still being found and removed 10 years later because of their reproductive behavior (i.e., eggs are laid underground and hatch at different times of the year).

The introduction pathway of Furcifer pardalis in Broward County is the pet trade. An open cage ideal for housing chameleons was found by MJC during a survey on 08 August 2013 at the northwestern corner of the North Creek Presbyterian Church, and this may be where the introduction occurred. Chamaeleo calyptratus is established in several locations in Florida (Krysko et al. 2004, 2011; Gillette and Krysko 2012) as is at least one population of Furcifer oustaleti (Gillette et al. 2010), and both of these species are intentionally being translocated to new sites (Ruben Ramirez, pers. comm). Two specimens of Chamaeleo senegalensis and one specimen of Trioceros melleri also have been found in Florida, but these appear to be waifs, and reproduction is not believed to have occurred in the wild (Krysko et al. 2011).

In this case, a cooperative interagency approach resulted in the early detection of Furcifer pardalis in Florida and ensured a rapid response to an introduced but hopefully not established population. Short of prevention, early detection and rapid response is the most effective way to deal with nonnative species (Wittenberg and Cock 2001). We recommend continued surveys of Helene Klein Nature Preserve and surrounding areas with the goal of eradicating the population as we determine if reproduction and dispersal are occurring. Chamaeleo calyptratus has tentatively been eradicated in Hawai'i (Mahnken and Radford 2011), demonstrating that the extirpation of an exotic chameleon species from an area it has invaded appears to be possible. The earlier the effort is made, the more likely eradication is, and action should be taken now while the problem is manageable.

\section{Acknowledgments}

We thank Seth Farris, Michiko Squires, Alissa Gulette, and Linda Briggs for assistance with surveys. North Creek Presbyterian Church granted us permission to survey their property and provided valuable specimen information. Our Lady of the Sign Catholic Church also granted us permission to access their property. Christopher V. Anderson graciously confirmed identification of photographed specimens. Ruben Ramirez supplied information on introduced lizard translocations, and Gad Perry, Robert Powell, Kevin Enge, Kristen Sommers, Doc Kokol, and an anonymous reviewer provided helpful comments on this paper.

\section{Literature Cited}

Andreone, F., F.M. Guarino, and J.E. Randrianirina. 2005. Life history traits, age profile, and conservation of the Panther Chameleon Furcifer pardalis (Cuvier 1829), at Nosy Be, NW Madagascar. Tropical Zoology 18:209-225.

Gillette, C.R. and K.L. Krysko. 2012. New county record for the Veiled Chameleon, Chamaeleo calyptratus Duméril and Bibron 1851 (Sauria: Chamaeleonidae), in Florida. Reptiles \& Amphibians 19:130-131.

Gillette, C.R., K.L. Krysko, J.A. Wasilewski, G.N. Kieckhefer III, E.F. Metzger III, M.R. Rochford, D. Cueva, and D.C. Smith. 2010. Oustalet's Chameleon, Furcifer oustaleti (Mocquard 1894) (Chamaeleonidae), a non-indigenous species newly established in Florida. Reptiles \& Amphibians 17:248-249.

Krysko, K.L., K.M. Enge, and F.W. King. 2004. The Veiled Chameleon, Chamaeleo calyptratus: A new exotic lizard species in Florida. Florida Scientist 67:249-253.

Krysko, K.L., J.P. Burgess, M.R. Rochford, C.R. Gillette, D. Cueva, K.M. Enge, L.A. Somma, J.L. Stabile, D.C. Smith, J.A. Wasilewski, G.N. Kieckhefer III, M.C. Granatosky, and S.V. Nielsen. 2011. Verified non-indigenous amphibians and reptiles in Florida from 1863 through 2010: Outlining the invasion process and identifying invasion pathways and stages. Zootaxa 3028:1-64.

Mahnken, B. and A. Radford. 2011. Eradicated? Maui menace meets maker. Abstract. 2011 Hawai'i Conservation Conference, 2-4 August 2011. Honolulu, Hawai' i.

Wittenbert, R. and M.J.W. Cock. 2001. Invasive Alien Species: A Toolkit for Best Prevention and Management Practices. CAB International, Wallingford, UK. 